\title{
Acute Nontraumatic Spinal Subdural Hematoma due to Warfarin
}

\section{Warfarine bağlı akut nontraumatic spinal subdural hematom}

\author{
Hakan $\mathrm{Ak}^{1}$, Tugay Atalay ${ }^{1}$, Yurdanur $\mathrm{Akyuz}^{2}$, Sinan Karacabey ${ }^{3}$
}

${ }^{1}$ School of Medicine, Department of Neurosurgery, Bozok University, Yozgat/Turkey.

${ }^{2}$ School of Medicine, Department of Radiology, Bozok University.

${ }^{3}$ School of Medicine, Clinic of Emergency Medicine, Bozok University

\section{Corresponding Author:}

\section{Dr Hakan Ak}

School of Medicine, Department of Neurosurgery, Bozok University, Yozgat /Turkey.

Tel: 0903542127060 (3671-3682)

\section{email:}

nrsdrhakanak@yahoo.com

Başvuru Tarihi/Received : 10-02-2015

Düzeltme Tarihi/Revised:

\section{1-02-2015}

Kabul Tarihi/Accepted:

15-02-2015

\section{Dear editor,}

Acute nontraumatic spinal subdural hematoma is a very rare pathology and may lead do disastrous consequences due to the compression of spinal cord and/or cauda $(1,2)$. Anticoagulant drugs, bleeding disorders (hemophilia, leukemia, and thrombocytopenia), acupuncture, spinal or epidural anesthesia, lumbar punctures, and spinal surgery, vascular malformations, and tumors have been identified in its etiology $(1,3,4)$. Patients may present with different clinical signs and symptoms according to the level of the pathology.

A 77-year-old woman attended to the emergency department with sudden onset severe back and low back pain with accompanying bilateral lower limb weakness and loss of sensation. There was no history of preceding trauma or any malignancy. Her medical history was unremarkable except atrial fibrillation. She was using warfarin due to atrial fibrillation for 3 years.

In neurological examination, cranial nerve examinations were normal. She was agitated. There was a flaccid paraplegia. Muscle power was 1/5 in both legs. There was anesthesia below Th10 level. Knee and ankle reflexes were absent bilaterally. She had reduced perianal sensation and anal tone, as well as absent voluntary anal contraction. She also had urinary retention. Peripheral blood tests showed an international normalized ratio (INR) of 1.8. Complete blood count tests, kidney and liver functions tests were in normal.

Magnetic resonance imaging (MRI) of thoracolumbar spine was planned based on the neurological examination. They revealed a hyperintense intradural lesion between Th11 and L2 (Fig 1a\&b). Contrast enhanced images didn't reveal any intradural lesion except hematoma. Due to relatively high INR level, 3 units of fresh frozen plasma and $10 \mathrm{mg}$ of vitamin $\mathrm{K}$ were administered intravenously. After this administration, INR was decreased to 0.9 and we planned to perform an operation. In the operation laminectomy was performed, epidural space was normal. However, dura was tense and bluish in color. After laminectomy, dura was opened from the midline and coagulated hematoma was seen (Fig. 2). Hematoma was evacuated until spinal cord appeared normal both in cranial and caudal directions. Motor weakness doesn't return to the normal level in spite of efficient evacuation of the hematoma. Unfortunately, patient was referred to physical therapy and rehabilitation with the same preoperative neurological findings.
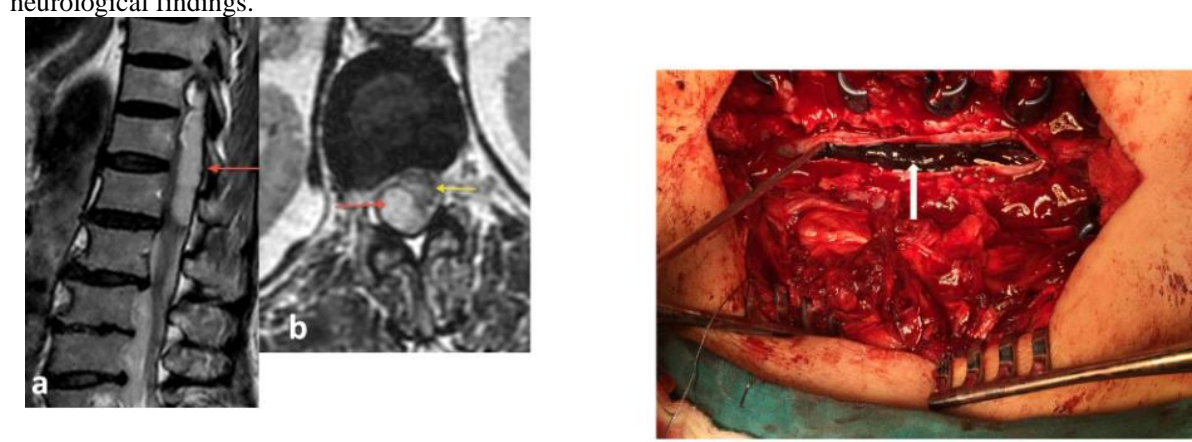

Fig. 1: (a) T2 weighted MR image of thoracolumbar spine on sagittal plane (red arrow indicating intradural hematoma) (b) T2 weighted MR image on axial plane (red arrow indicating hematoma, yellow arrow indicating intact spinal cord).

The mechanism of development of spinal subdural hematoma is not clear due to some reasons. The anatomical spaces in the spine are less identified compared to cranium and it is not clear the existence of a real or only potential subdural space. Moreover, there no major blood vessels or bridging veins unlike the epidural or intracranial subdural space (1).

Anticoagulant drugs have been identified in the etiology of acute nontraumatic spinal subdural hematoma. The number of new cases is increasing with the increased use of them around the worldwide. It is was reported that the risk of bleeding increases as INR rises for warfarin treated patients, particularly if the INR exceeds for 4 (5). Recently, Bruce-brand et al reported a similar case whose INR was 6 (1). However, INR was 1.8 in our patient. increase in INR.

We want to emphasize that spinal subdural hematoma may develop even though only a slight References
Bruce-Brand RA, Colleran GC, Broderick
JM, Lui DF, Smith EM, Kavanagh EC, Poynton AR. The
Journal of Emergency Medicine. Acute nontraumatic spinal
intradural hematoma in a patient on warfarin. 2013;
45(5):695-687.
2. Domenicucci M, Ramieri A, Ciappetta P,
Delfini R. Nontraumatic acute spinal subdural hematoma:
report of five cases and review of the literature. J Neurosurg
1999;91:65-73. 3. Morandi X, Riffaud L, Chabert E, Brassier G.
Acute nontraumatic spinal subdural hematomas in three patients.
Spine. 2001; 26(23):e547-e551.
4. Park J, Ahn R, Son D, Kang B, Yang D. Acute
spinal subdural hematoma with hemiplegia after acupuncture : a
case report and review of the literature. Spine J. 2013;13:e59-e63.
$5 . \quad$ Garcia DA, Regan S, Crowther M, Hylek EM. The
risk of hemorrhage among patients with warfarin-asscoiated
coagulopathy. J Am Coll Cardiol. 2006;47(4):804-808. 